\title{
Variable Speed Wind Turbines Capability for Temporary Over-Production
}

\author{
Tarnowski, Germán Claudio; Kjær, Philip Carne; Sørensen, Poul Ejnar; Østergaard, Jacob
}

Published in:

IEEE PES General Meeting

Link to article, DOI:

10.1109/PES.2009.5275387

Publication date:

2009

Document Version

Publisher's PDF, also known as Version of record

Link back to DTU Orbit

Citation (APA):

Tarnowski, G. C., Kjær, P. C., Sørensen, P. E., \& Østergaard, J. (2009). Variable Speed Wind Turbines Capability for Temporary Over-Production. In IEEE PES General Meeting (pp. 1-7). IEEE.

https://doi.org/10.1109/PES.2009.5275387

\section{General rights}

Copyright and moral rights for the publications made accessible in the public portal are retained by the authors and/or other copyright owners and it is a condition of accessing publications that users recognise and abide by the legal requirements associated with these rights.

- Users may download and print one copy of any publication from the public portal for the purpose of private study or research.

- You may not further distribute the material or use it for any profit-making activity or commercial gain

- You may freely distribute the URL identifying the publication in the public portal 


\title{
Variable Speed Wind Turbines Capability for Temporary Over-Production
}

\author{
Germán Claudio Tarnowski, Philip Carne Kjær, Poul E. Sørensen and Jacob Østergaard
}

\begin{abstract}
New control systems for Variable Speed Wind Turbines (VSWT) need to be developed in order to provide inertia response and frequency control to support the grid. This work studies the behavior and capability of VSWT for providing temporary active power overproduction. The study is conducted on a multimegawatt VSWT with Doubly-Fed Induction Generator. It was found that it is possible to have an active power overproduction of 0.2 pu for at least 10 seconds, which could be useful for the grid operator for restoring a critical situation of grid frequency dip. Nevertheless it is important to be aware about the underproduction power and the associated recovery period that follow a VSWT overproduction operation. The results can be used in designing suitable control systems for VSWT inertia response and frequency control.
\end{abstract}

Index Terms - Active power, ancillary services, frequency control, frequency response, inertia, overproduction, variable speed wind turbines, wind power integration.

\section{NOMENCLATURE}

$\mathrm{T}_{\mathrm{t}}$ : mechanical torque developed in the turbine blades [pu]

$\mathrm{P}_{\mathrm{tN}}$ : rated wind turbine power $[\mathrm{pu}]$

$\mathrm{V}_{\mathrm{w}}$ : actual wind speed [pu]

$\omega_{\mathrm{t}}$ : wind turbine rotational speed $[\mathrm{pu}]$

$\mathrm{C}_{\mathrm{P}}$ : power coefficient

$\mathrm{C}_{\mathrm{PN}}$ : rated power coefficient

$\lambda: \quad$ tip-speed ratio

$\beta$ : $\quad$ pitch angle

Other variables and parameters are defined along the text.

This work was supported by Technical University of Denmark and by Vestas Wind Systems A/S.

Germán C. Tarnowski is with the Centre for Electric Technology, Technical University of Denmark and also with Vestas Wind System A/S, (e-mail: gctar@vestas.com).

Jacob Østergaard is with the Centre for Electric Technology, Technical University of Denmark (e-mail: joe @elektro.dtu.dk).

Poul. E. Sørensen is with the Wind Energy Department at Risø National Laboratory for Sustainable Energy, Technical University of Denmark, (e-mail: poul.e.soerensen@risoe.dk).

Philip. C. Kjær is with Vestas Wind Systems A/S, Denmark (e-mail: pck@vestas.com).

\section{INTRODUCTION}

$\mathrm{W}$ IND power is an important source of electricity generation. Modern wind farms are equipped with Variable Speed Wind Turbines (VSWT) which have to fulfill increasingly demanding grid codes requirements $[1,2]$. As the power system dependency on wind power increases, wind power generation will have to contribute with services that are normally delivered by conventional synchronous generation [3]. In power systems with high wind power penetration, wind power generation will have to provide with a reliable and repeatable frequency response to support the grid and decrease costs of reserve power. Considering the operation of small isolated power systems as found in islands [4], frequency reserves can be more valuable to the system than maximizing the wind power generation yield.

The most common VSWT types are the Doubly-Fed Induction Generator (DFIG) based and the Synchronous Generator Full Converter (SGFC) based. The VSWT technology presents flexibility for very fast (decoupled) control of generated active and reactive powers [2, 5-9]. With these characteristics, VSWT can be used to provide ancillary services which are normally provided by conventional synchronous generators. Extra active power output from VSWT can be injected to the grid during, e.g., initial stages of a significant downward frequency event, improving the frequency stability in power systems with high wind power penetration [10].

Several recent works that have studied VSWT's inertia response and frequency control can be found in the literature, e.g. [5-9]. With the wind turbine extracting the available power from the wind, it is possible to generate a temporary active power overproduction, which mainly depends on rotational speed variations, mechanical inertia and wind speed conditions. Nevertheless further studies on VSWT's capabilities for providing active power overproduction are necessary for developing suitable control systems and supporting grid operators.

In this work the capability of VSWT-DFIG for providing temporary extra active power output for grid support is studied. A control mechanism for VSWT overproduction demand is implemented which is activated with a frequency dip. The main characteristic parameters describing the VSWT overproduction operation as well as the main wind turbine variables are assessed for different overproduction levels and 
wind speed conditions. Computational simulations were carried out in Simulink/Matlab®.

The paper is organized as follows. Section III briefly presents the modeling structure. The simulation set up is described in Section IV. Simulation results illustrating the VSWT overproduction behavior are provided in Section V. Finally, conclusions are presented in Section VI.

\section{WIND TURBINE MODELING AND CONTROLLER}

In this section a brief description of the wind turbine modeling and control system for the analysis is presented.

\section{A. Wind Turbine Modeling}

A 2MW VSWT-DFIG was investigated. The VSWT-DFIG is equipped with a bidirectional power converter in the DFIG rotor circuit and blade angle control system (pitch-control), allowing variable-speed-constant-frequency electric power generation.

The aerodynamic model establishes the mechanical torque developed in the blades, dependent on the wind speed, the turbine rotational speed and the blades angle. In per unit system (pu) this relation is as follows [2]:

$$
\mathrm{T}_{\mathrm{t}}=\frac{\mathrm{P}_{\mathrm{tN}}}{\mathrm{C}_{\mathrm{PN}}} \mathrm{C}_{\mathrm{P}}(\lambda, \beta) \frac{\mathrm{V}_{w}^{3}}{\omega_{\mathrm{t}}} ;
$$

In this work the characteristic of the $C_{P}(\lambda, \beta)$ coefficient was modeled as a look up table. Figure 1 shows the $C_{P}(\lambda, \beta)$ characteristic for two different values of $\beta$ (pitch control).

The mechanical system was represented by a two lumpedmass model. The DFIG was represented by a $3^{\text {rd }}$ order algebraic-differential model, expressed in the synchronous $d$ $q$-axis reference frame and neglecting the stator flux transients [2]. The DFIG rotor side converter was represented by a controllable ideal voltage source in the synchronous frame, generating $v_{d r}$ and $v_{q r}$ for the DFIG rotor. The grid side converter was represented by a controllable current source in the synchronous frame, injecting currents to the grid. Power losses in the converters were neglected and it was considered that there was no energy variation in the DC-link, so the active power generated in the DFIG rotor equaled the active power produced by the grid side converter [2]. Wind speed, stator voltage and reactive current reference were kept constant during the simulations.

\section{B. Wind Turbine Control System}

The DFIG rotor currents are controlled through the rotor voltages in the synchronous reference frame by PI controllers. The total active and reactive powers of the VSWT-DFIG are controlled through the rotor currents by PI controllers. The basic principle of the control mechanism for VSWT overproduction demand implemented for this study is described in the next section.

The VSWT allows maintaining the turbine's tip-speed ratio in the optimal value, $\lambda_{o p}$, for wind speeds below the rated value. This is the concept of the maximum production strategy, which is characterized by $\beta=0, \lambda=\lambda_{o p}$ and, therefore, $\mathrm{C}_{\mathrm{P}}=\mathrm{C}_{\mathrm{Pmax}}$. In this state, the wind turbine generates the maximum available power, namely $\mathrm{P}_{\mathrm{Av}}$. For high wind speeds the generated active power is kept constant and the rotational speed is limited by the pitch control system, whose simplified model is shown in Fig. 2.

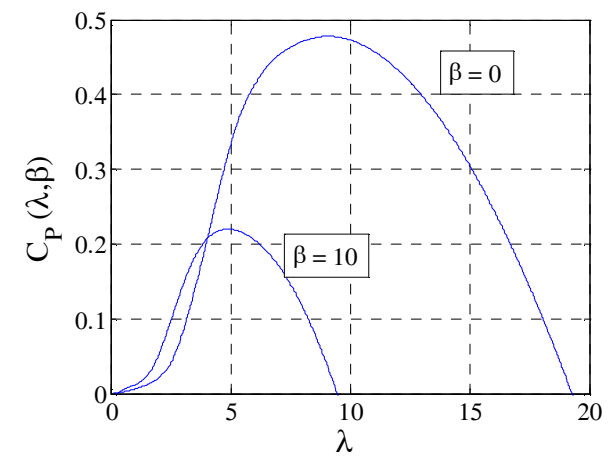

Fig. 1. Wind turbine aerodynamic coefficient.

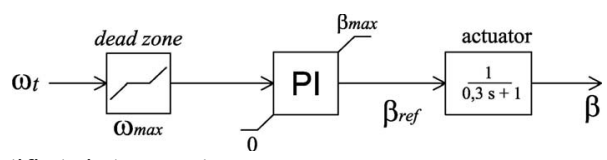

Fig. 2. Simplified pitch control system.

\section{Simulation Set UP}

As the objective of the work is to evaluate the dynamic capability of the variable speed wind turbine for providing an extra active power output a simulation set up has been designed. In this work, the way of assessing the VSWT capability for active power overproduction is by applying a step on the actual active power reference during a time period determined by a critical variable.

When an extra power output is required due to some grid event, e.g. grid frequency dip, the VSWT extra active power function is activated. This function increases the actual active power set point by adding an Over-Production value $\Delta \mathrm{P}_{\mathrm{OP}}$ on top of the pre-event active power reference. The electrical power output is then given by:

$$
\mathrm{P}_{\mathrm{e}}=\mathrm{P}_{\mathrm{e} 0}+\Delta \mathrm{P}_{\mathrm{OP}}
$$

Where $\mathrm{P}_{\mathrm{e}}$ is the generated active power and $\mathrm{P}_{\mathrm{e} 0}$ is the preevent power reference. For low wind speeds, $\mathrm{P}_{\mathrm{e} 0}$ equals to the available wind power $P_{A v}$, but $P_{e 0}$ has a maximum (rated) limit for high wind speeds. The change on the DFIG rotor side converter active power set point is done through a ramp limiter of $1 \mathrm{pu} / \mathrm{s}$. The situation described by (2) means that the VSWT production is higher than the available wind power and that there is an imbalance between mechanical input and electrical output. The extra power $\Delta \mathrm{P}_{\mathrm{OP}}$ is taken from the kinetic energy stored in the WT rotating masses.

Figure 3 shows the VSWT power vs. rotational speed. The black line represents the mechanical power from the blades vs. 


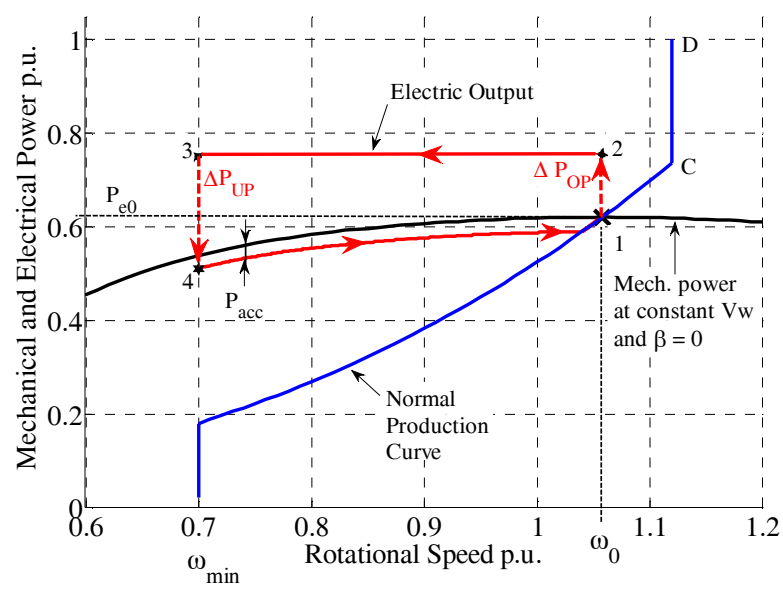

Fig. 3. WT power vs. rotational speed. The blue line is the WT normal (static) production power. The black line is the blade's mechanical power for a constant wind speed. The red line is the electric power set point for over-production process.

rotational speed for a given wind speed and fixed pitch angle $(\beta=0)$. The red line represents the generated electric power $\mathrm{P}_{\mathrm{e}}$. The blue line represents the normal production (set point) of the VSWT for the normal range of wind speeds.

In normal conditions, the VSWT is operating at some point on the Normal Production Curve, which depends on the actual wind speed, e.g. at point 1 in Fig. 3, producing the available power from the wind at rotational speed $\omega_{0}$. If we desire to have an Over-Production in a quantity $\Delta \mathrm{P}_{\mathrm{OP}}$ by a relatively fast change of the converter set point, we go from point 1 to 2 in the Fig. 3. In this new situation the rotational speed will start decreasing due to the imbalance in mechanical and electromechanical torques (at this point it is impossible to increase the mechanical power by pitching the blades because the VSWT was already generating the maximum possible). The imbalance in powers is increasing due to the decrease in the mechanical power (decrease in the aerodynamic efficiency for the given wind speed) as it can be seen in Fig. 3 when the operating point moves from 2 towards 3 , while the electrical output $\mathrm{P}_{\mathrm{e}}$ is kept constant. In this study the minimum rotational speed $\omega_{\min }$ of $0.7 \mathrm{pu}$ is chosen as the limit criterion ( $1 \mathrm{pu}$ corresponds to the generator synchronous speed). At the moment of reaching $\omega_{\min }$ the VSWT power control system changes the power set point from 3 to 4 , so the generated power is below the mechanical power in a quantity $\mathrm{P}_{\text {acc }}$. The value of $P_{\text {acc }}$ produces the acceleration of the machine back to the previous normal operating point 1 for the given wind (if the wind speed has changed during this operation, the point 1 will be situated at other place on the Normal Production Curve). In this work, the described process is called "overproduction operation". If the VSWT is normally producing the available power from the wind then the overproduction process is characterized by an "overproduction period" (line 2-3 in Fig. 3) followed by an "underproduction period" (line 4-1 in Fig. 3), where the active power production is less that the pre-event generated power.

Figure 4 shows the basic principle of the control mechanism for the overproduction demand implemented in this work. The

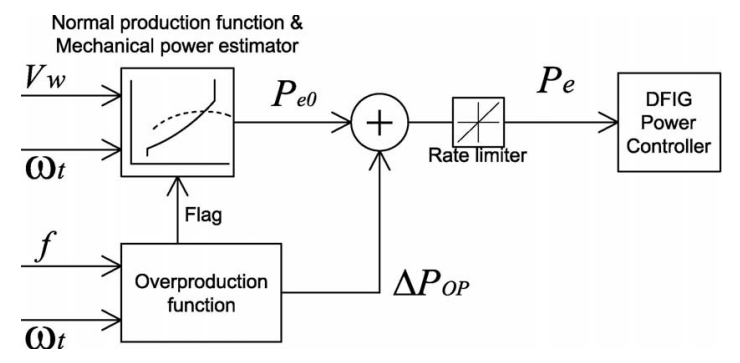

Fig. 4. Basic principle of the control mechanism for the overproduction demand study.

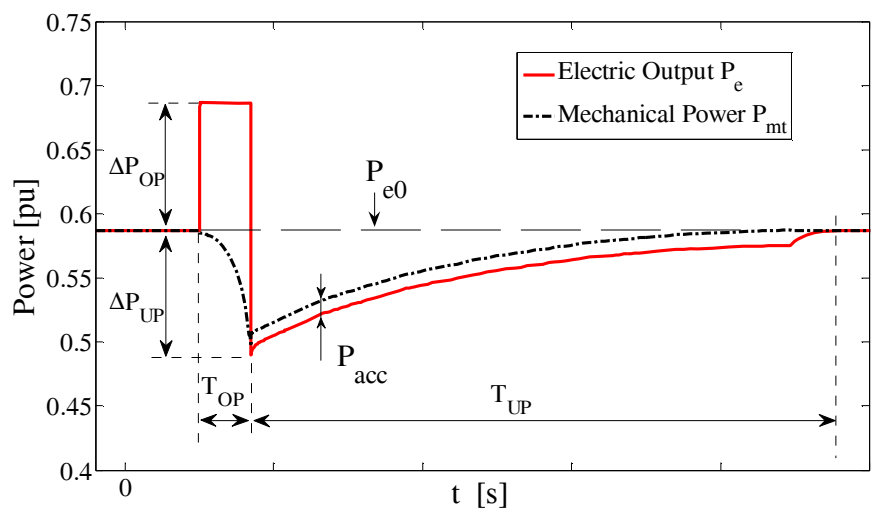

Fig. 5. Characteristic parameters describing the overproduction operation.

overproduction function block is measuring the grid frequency $f$. When the frequency dip is detected, the $\Delta \mathrm{P}_{\mathrm{OP}}$ value is added. Once the overproduction function block detects the $\omega_{\min }$ rotational speed, the overproduction period is finished and the wind turbine is "released". The mechanical power is obtained through and estimator and then the active power reference can be adjusted for a given $\mathrm{P}_{\text {acc }}$.

Figure 5 shows the overproduction process of Fig. 3 in the time domain, where the main characteristic parameters are also defined. Previous to the event, the captured mechanical power $\mathrm{P}_{\mathrm{mt}}$ is equal to the generated electrical power $\mathrm{P}_{\mathrm{e}}$ (neglecting the internal losses in the WT for the analysis). But during the event there is a mismatch between the electrical power and the mechanical power as the rotational speed is varying. In Fig. 5, $\mathrm{P}_{\mathrm{e} 0}$ is the normal operating power (available) for the given wind speed; $\Delta \mathrm{P}_{\mathrm{OP}}$ is the OverProduction power step which is the amount of extra active power on top of the available wind power; $\mathrm{T}_{\mathrm{OP}}$ is the overproduction period in which it is possible to provide the extra power output $\Delta \mathrm{P}_{\mathrm{OP}}$ before reaching the minimum rotational speed of $0.7 \mathrm{pu} ; \Delta \mathrm{P}_{\mathrm{UP}}$ is the Under-Production power decrease which is the amount of generated power that is decreased right after the overproduction period for creating the accelerating power; $T_{U P}$ is the underproduction period in which the WT has to produce less power than the available in order to accelerate the rotational speed for recovering the normal operating point; $\mathrm{P}_{\text {acc }}$ is the accelerating power which is the difference between the actual mechanical power generated in the blades and the electrical power output, according to the following equation:

$$
\mathrm{P}_{\text {acc }}=\mathrm{P}_{\mathrm{mt}}-\mathrm{P}_{\mathrm{e}}
$$


In this work the value of $\mathrm{P}_{\mathrm{acc}}$ was kept constant during the underproduction period of $\mathrm{T}_{\mathrm{UP}}$, but other strategy can be implemented during the recovery period.

\section{RESULTS}

Figure 6 shows the dynamic simulation result of the overproduction process when applying an overproduction step of $\Delta \mathrm{P}_{\mathrm{OP}}=0.1 \mathrm{pu}$ and setting an accelerating power of $\mathrm{P}_{\mathrm{acc}}=$ $0.02 \mathrm{pu}$. The wind speed is $\mathrm{W}_{\mathrm{s}}=10 \mathrm{~m} / \mathrm{s}$ which is proximately equivalent to $\mathrm{P}_{\mathrm{e} 0}=0.59 \mathrm{pu}$ of continuous electric power. It is also shown the mechanical toque in the generator shaft, the mechanical torque in rotor blades and the WT rotational speed. In the figure it can be seen how the mechanical power is decreasing together with the rotational speed while the WT is injecting the extra electric power during an overproduction time of $\mathrm{T}_{\mathrm{OP}}=17 \mathrm{~s}$. When the rotational speed reaches the minimum value, the power controller is changing the reference to a value below the actual mechanical power. By setting $\mathrm{P}_{\mathrm{acc}}=0.02 \mathrm{pu}$ the electric output right after the overproduction period is $\mathrm{P}_{\mathrm{e}}=0.49 \mathrm{pu}$, that is $\Delta \mathrm{P}_{\mathrm{UP}}=0.1 \mathrm{pu}$. Notice that $\Delta \mathrm{P}_{\mathrm{UP}}$ is how much the power output is decreasing below the available power $\mathrm{P}_{\mathrm{e} 0}$ right after the overproduction period. The underproduction period is $\mathrm{T}_{\mathrm{UP}}=190 \mathrm{~s}$.

Figure 7 shows another simulation result similar to that shown in Fig. 6 but this time setting an accelerating power of $\mathrm{P}_{\mathrm{acc}}=0.04 \mathrm{pu}$. The wind speed and the overproduction step are the same as in the previous figure. It can be seen that the overproduction time does not change, which is obvious if the wind speed and overproduction step are the same as before. Instead the electrical power is decreasing to $P_{e}=0.47$ pu right after the overproduction time, that is $\Delta \mathrm{P}_{\mathrm{UP}}=0.12 \mathrm{pu}$. The underproduction period decreases approximately 2.3 times to $\mathrm{T}_{\mathrm{UP}}=80 \mathrm{~s}$.

In order to see how is the relationship between the characteristic values defined in Fig. 5 for different wind speed conditions, overproduction step and accelerating power, several simulations were carried out taking the overproduction power step $\Delta \mathrm{P}_{\mathrm{OP}}$, the wind speed $\mathrm{V}_{\mathrm{w}}$ and the accelerating power $\mathrm{P}_{\mathrm{acc}}$ as independent variables. The results are plotted as a family of curves from Fig. 8 to Fig. 16. For all the situations the WT was operating according to the normal operation curve (blue line in Fig. 3).

Figure 8 shows how the overproduction period depends on the overproduction power step for several low wind speed conditions $(7 \mathrm{~m} / \mathrm{s}$ to $11 \mathrm{~m} / \mathrm{s})$, when the blades angle is constant. The higher the overproduction step, the lower the overproduction period. It is interesting to notice that it is possible to have an overproduction of $0.2 \mathrm{pu}$ on top of a steady 0.8 pu for at least 10 seconds, which could be useful for the grid operator for restoring a critical situation of frequency dip, especially in power systems with slow primary movers response or low inertia. With the same wind speed, an overproduction of $+0.1 \mathrm{pu}$ can be hold for more then 15 seconds. Nevertheless it is important to be aware about the underproduction power and the associated underproduction period (recovery period) that follow an overproduction process.

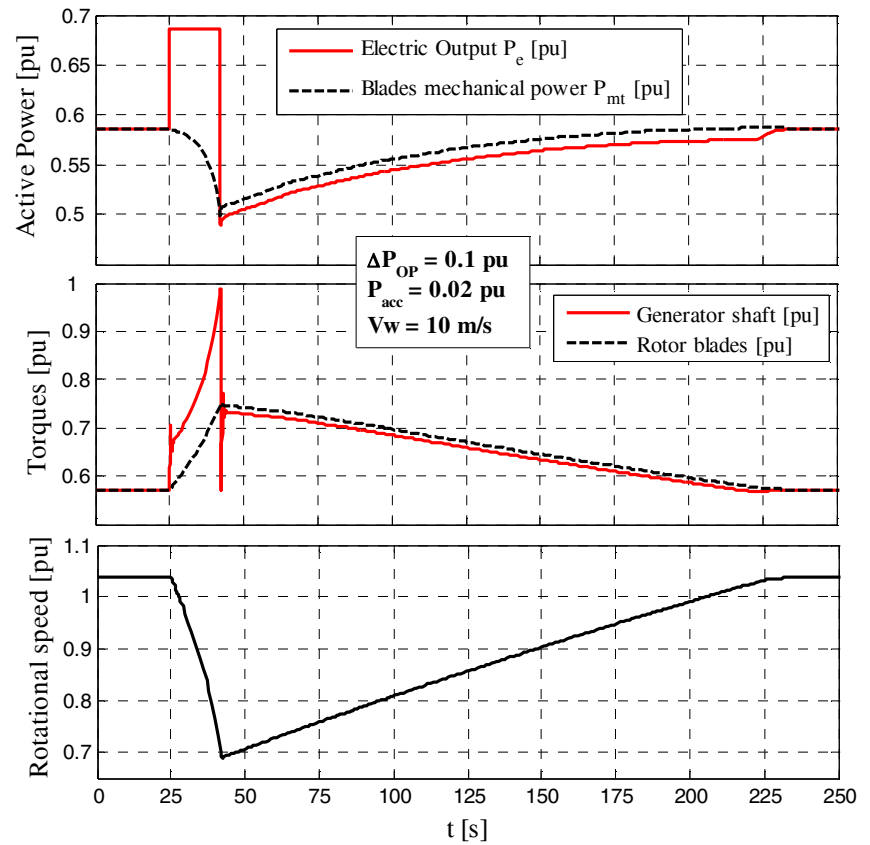

Fig. 6. Over-production process for $\Delta \mathrm{P}_{\mathrm{OP}}=0.1 \mathrm{pu}, \mathrm{P}_{\mathrm{acc}}=0.02 \mathrm{pu}$ and $\mathrm{P}_{\mathrm{e} 0}=0.59$ $\mathrm{pu}\left(\mathrm{V}_{\mathrm{w}}=10 \mathrm{~m} / \mathrm{s}\right)$, resulting in $\Delta \mathrm{P}_{\mathrm{UP}}=0.1 \mathrm{pu}, \mathrm{T}_{\mathrm{OP}}=17 \mathrm{~s}, \mathrm{~T}_{\mathrm{UP}}=190 \mathrm{~s}$.

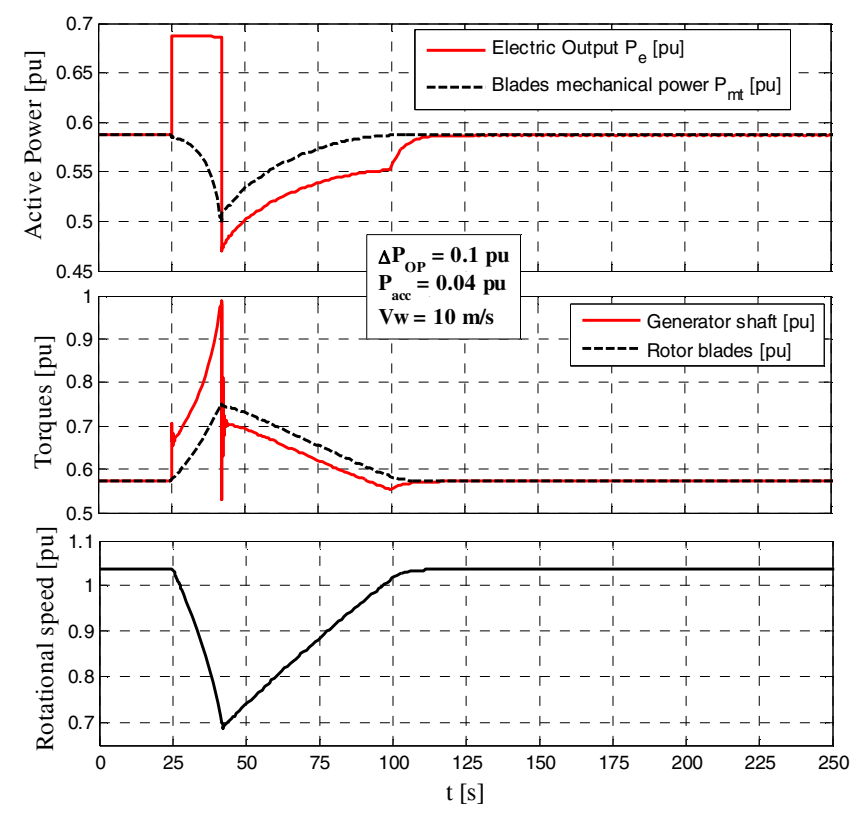

Fig. 7. Over-production process for $\Delta \mathrm{P}_{\mathrm{OP}}=0.1 \mathrm{pu}, \mathrm{P}_{\mathrm{acc}}=0.04 \mathrm{pu}$ and $\mathrm{P}_{\mathrm{e} 0}=0.59$ $\mathrm{pu}\left(\mathrm{V}_{\mathrm{w}}=10 \mathrm{~m} / \mathrm{s}\right)$, resulting in $\Delta \mathrm{P}_{\mathrm{UP}}=0.12 \mathrm{pu}, \mathrm{T}_{\mathrm{OP}}=17 \mathrm{~s}, \mathrm{~T}_{\mathrm{UP}}=80 \mathrm{~s}$.

The overproduction operation is possible only when the ratings of the components are respected. In that sense, a further decrease in the rotational speed might be possible with the consequent increase in the overproduction period.

Figure 9 is similar to Fig. 8 but showing results for a set of high wind speed conditions ( $12 \mathrm{~m} / \mathrm{s}$ up to $13 \mathrm{~m} / \mathrm{s}$ ), when the pitch control is limiting the rotational speed and $\mathrm{P}_{\mathrm{e} 0}=1 \mathrm{pu}$. Here the overproduction period capability is much higher for wind speeds over $12 \mathrm{~m} / \mathrm{s}$, nevertheless neither ratings nor load limitations of the machine were considered in the analysis. Having excess of wind, the overproduced electric power is counterbalanced by an increase in the mechanical power which 


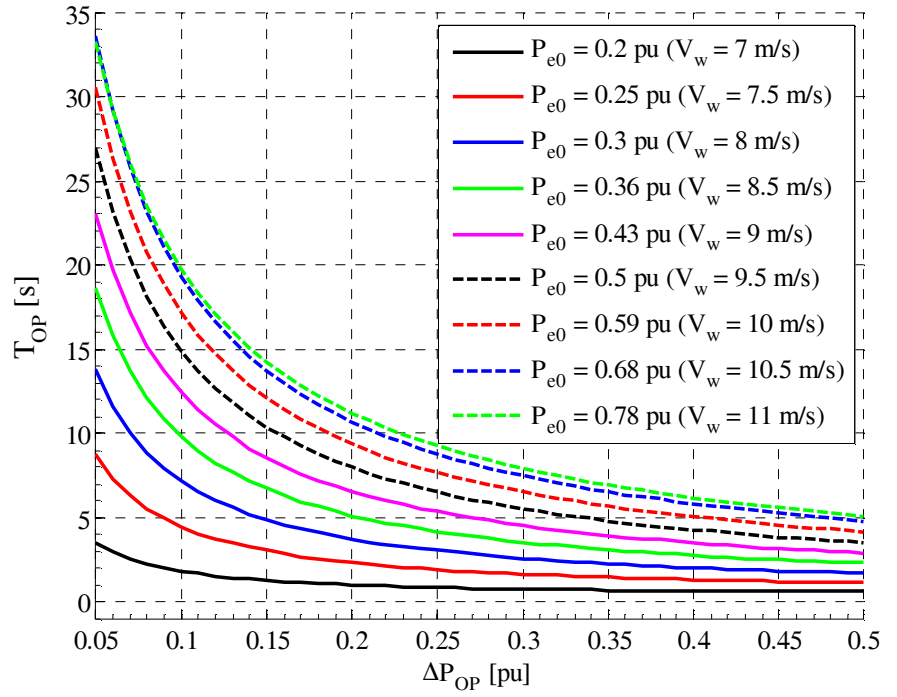

Fig. 8. Overproduction period vs. overproduction step for low wind speeds.

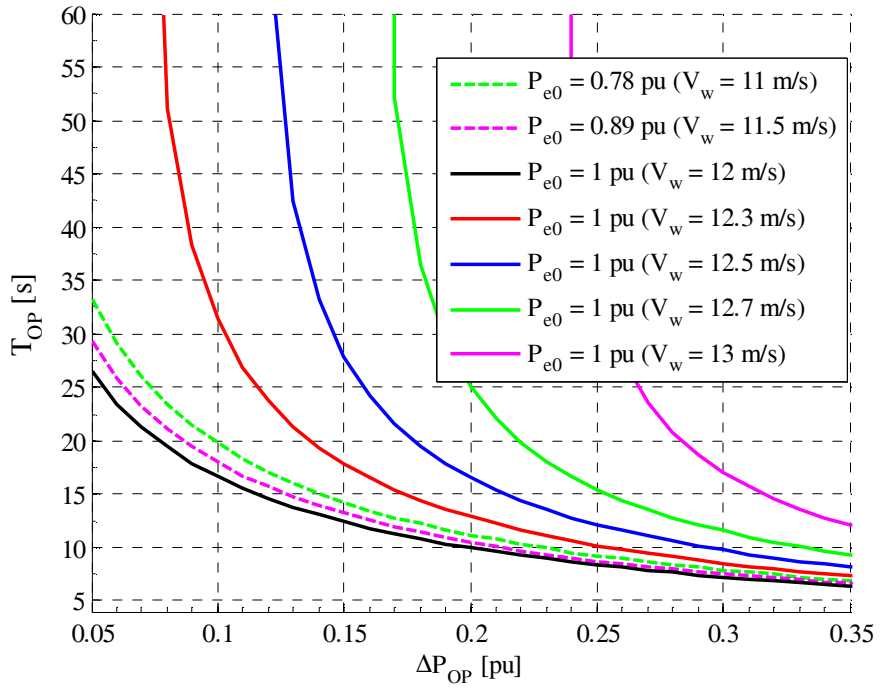

Fig. 9. Overproduction period vs. overproduction step for high wind speeds.

is done automatically when the pitch controller keeps the rotational speed.

For a given overproduction power step, the overproduction period increases as the wind speed (available power) increases, due to higher values of stored kinetic energy. Figure 10 shows this dependency for different overproduction power steps. It is interesting to notice how the overproduction period capability is decreasing when the wind speed increases in the range between $10.8 \mathrm{~m} / \mathrm{s}\left(\mathrm{P}_{\mathrm{e} 0}=0.75 \mathrm{pu}\right)$ and $12 \mathrm{~m} / \mathrm{s}\left(\mathrm{P}_{\mathrm{e} 0}=1 \mathrm{pu}\right)$, as can be seen in Fig. 10 This is because the stored kinetic energy does not change in that wind speed range, according to the line segment C-D in Fig. 3.

It is logical to think that the period of underproduction (time of acceleration) is independent of the overproduction step if a fixed minimum rotational speed is taken as the overproduction period criterion, as can be observed in Fig. 11. Nevertheless the underproduction period is slightly increasing with the overproduction step due to the rate change limiter in the power controller set point, which introduces more time for higher changes in the reference values.

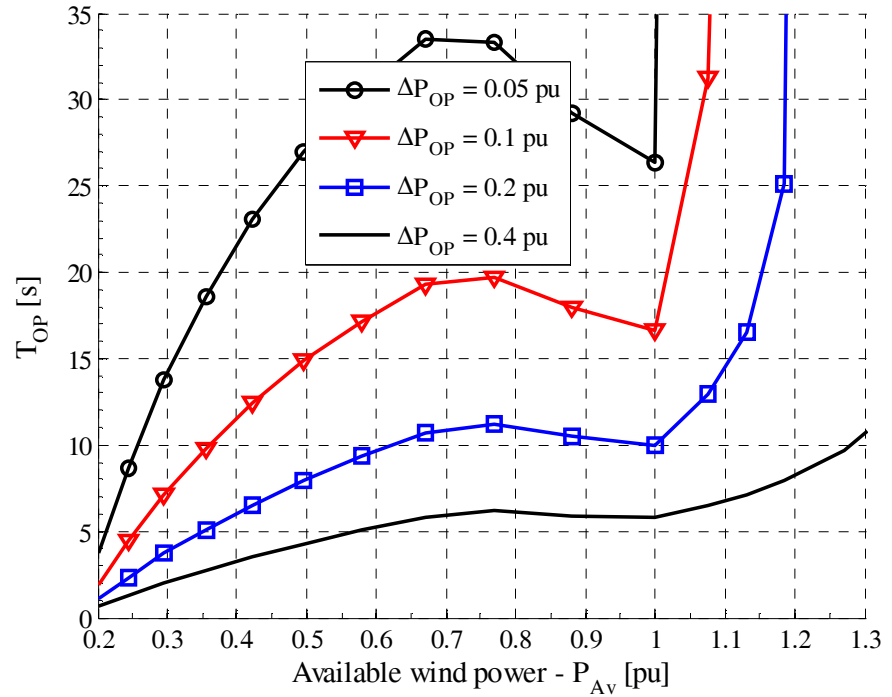

Fig. 10. Overproduction period vs. available wind power for different overproduction steps.

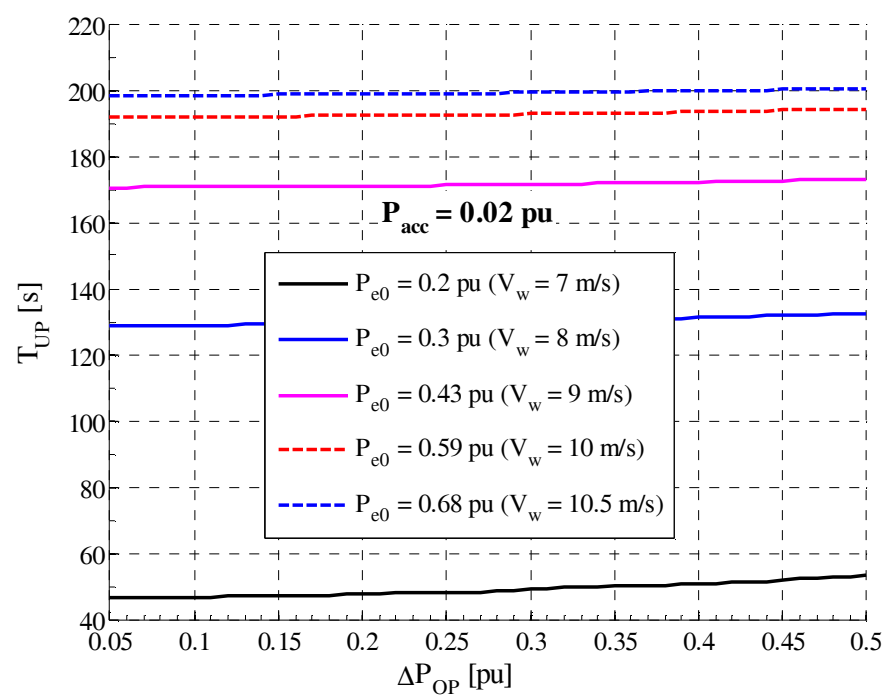

Fig. 11. Underproduction period (acceleration) vs. overproduction step for different available wind power.

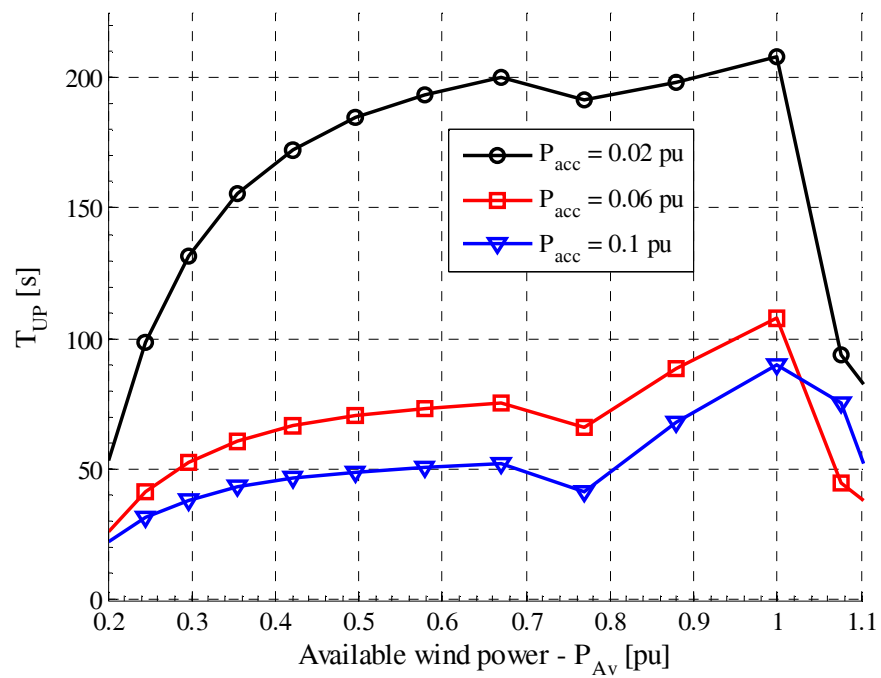

Fig. 12. Underproduction period (acceleration) vs. available wind power for different accelerations. 


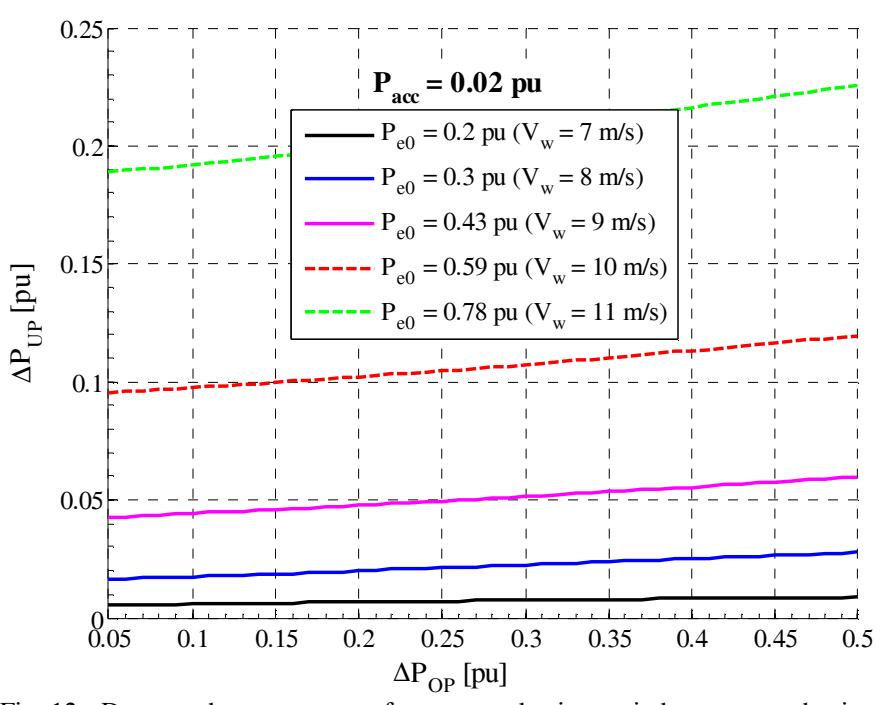

Fig. 13. Decreased power output after overproduction period vs. overproduction step for different available wind powers.

The underproduction period is then highly dependent on the accelerating power $\mathrm{P}_{\mathrm{acc}}$ and the available wind power as can be seen in Fig. 12, especially for low available wind power. It can be noticed that for a given accelerating power, the underproduction period is stabilizing in a middle range available wind power. For available wind power higher than the nominal value, the underproduction period is decreasing drastically as consequence of the pitch actuation. It can be noticed also the non linear dependency on the accelerating power.

Similarly to the underproduction period dependency on the overproduction step shown in Fig. 11, the amount of decreased electrical power right after the overproduction period is slightly dependent on the overproduction step if a fixed minimum rotational speed is taken as the overproduction time criterion, as can be observed in Fig. 13. It has to be taken into account that the decrease in the electrical power is determined using an estimator of the available mechanical power and the desired accelerating power value.

The mechanical power estimator will provide the same value for similar set of rotational speed, wind speed and pitch angle. In Fig. 13, the variations in $\Delta \mathrm{P}_{\mathrm{UP}}$ when increasing $\Delta \mathrm{P}_{\mathrm{OP}}$, especially for high wind speeds, are due to the rate change limiter of the power controller set point, which introduces more time for higher changes in the reference values. This delay produces a slightly higher excursion of the rotational speed beyond the minimum value of $0.7 \mathrm{pu}$, which is observed by the mechanical power estimator and finally reflected in the amount of electrical power that needs to be decreased for producing the desired accelerating power.

The underproduction power decrease is then highly dependent on the accelerating power and the available wind power as can be seen in Fig. 14.

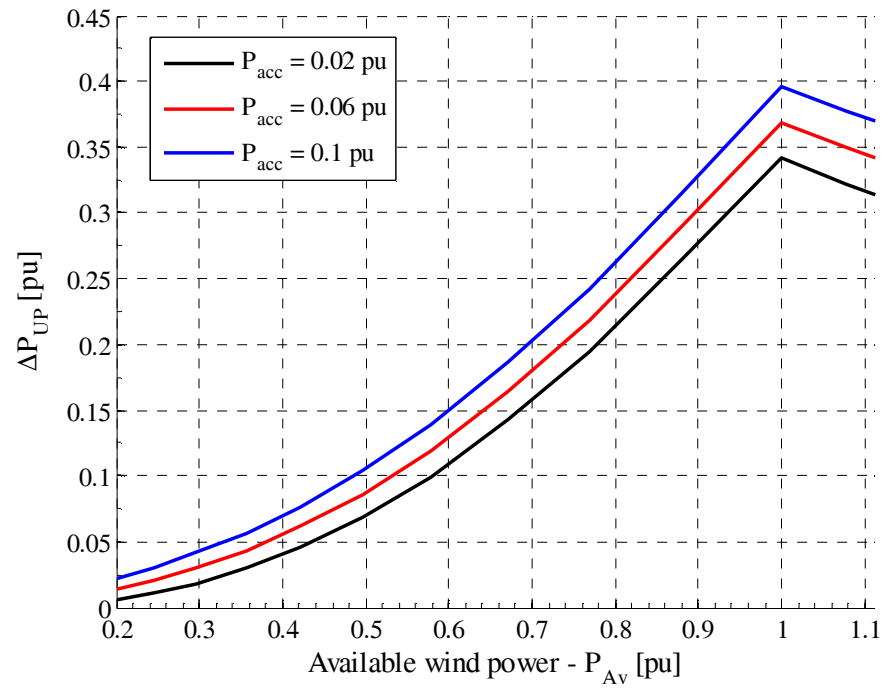

Fig. 14. Decreased power output after overproduction vs. available wind power for different accelerations.

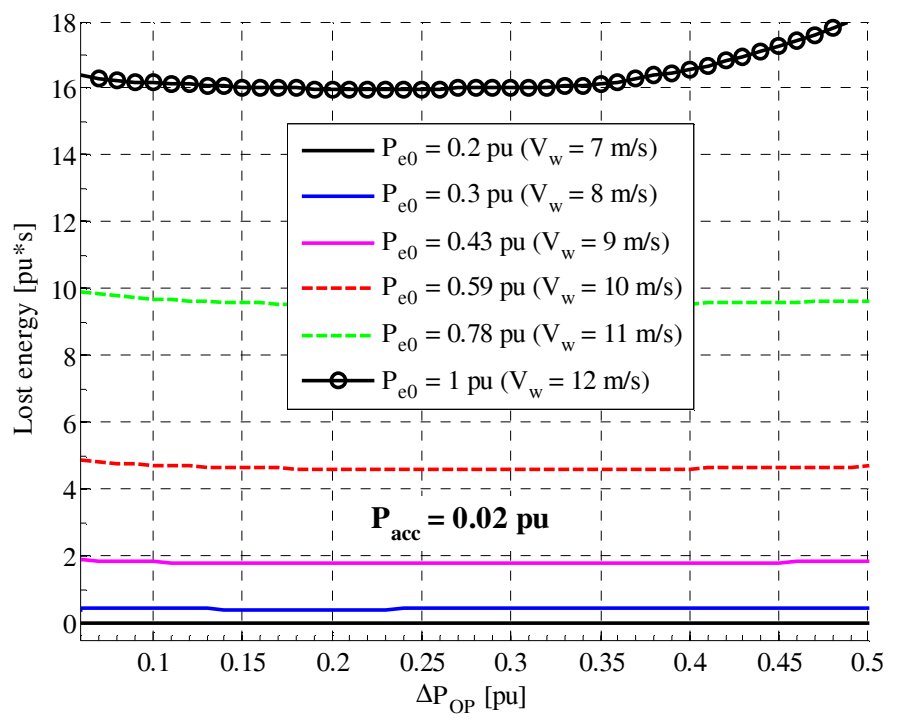

Fig. 15. Lost energy during overproduction process vs. overproduction step for different available wind powers.

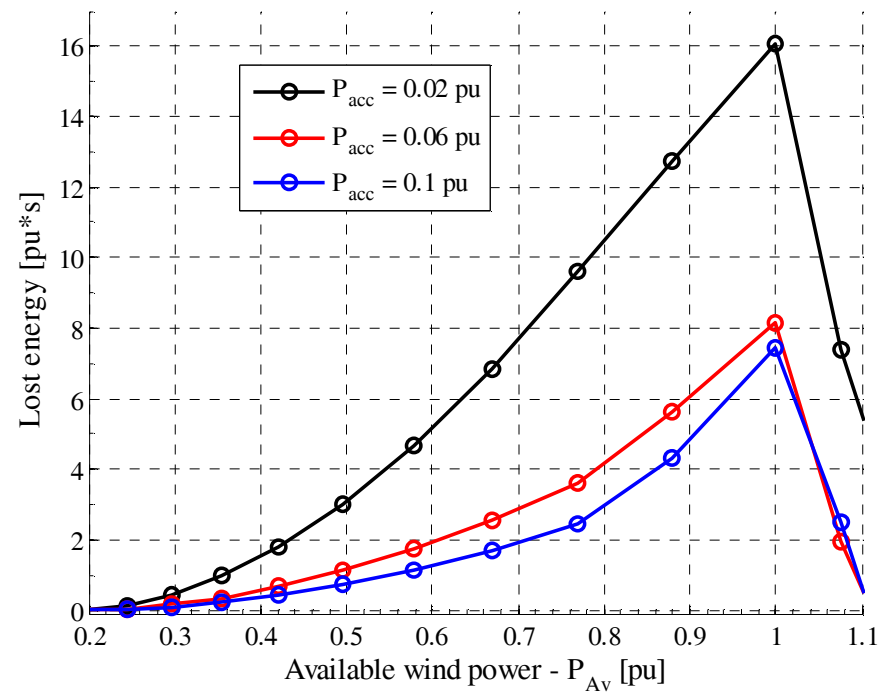

Fig. 16. Lost energy during overproduction process vs. available wind power for different accelerations 
It can be noticed for a given accelerating power, the underproduction power decrease is increasing linearly in a middle range available wind power, between $0.6 \mathrm{pu}$ and $1 \mathrm{pu}$. For higher values of available wind power the underproduction step is decreasing drastically as a consequence of the pitch actuation. It can be observed also the non linear dependency on the accelerating power.

Similar observations can be made on the lost energy. The lost energy is the energy that is not generated if the wind turbine has to perform an overproduction process as defined in Fig. 3, in contrast with the energy that is produced if the WT is just operating normally producing the available power.

Figure 15 presents the lost energy against the overproduction step. The lost energy is almost independent of the overproduction step except for high wind speeds. For a given wind speed and accelerating power, the area under the electrical power curve in Fig. 6 or Fig. 7 is invariant for different overproduction steps.

By increasing the accelerating power the period of underproduction is reduced (Fig. 12), allowing the wind turbine to recover the optimal operating point faster. The lost energy is then reduced, as can be seen in Fig. 16, where the dependency of the lost energy on the available wind power is also shown. The lost energy depends almost linearly on the available power (wind speed). But it is non linear with the accelerating power.

With a bigger VSWT inertia constant the overproduction period can be higher for a given overproduction step, because the stored kinetic energy would be higher. But the recovery period will also be higher in order to recover the released kinetic energy.

For a complete assessment of the overproduction capabilities of the machine, the limits of the electrical and mechanical elements have to be included, considering especially the loads on the blades and drive train. It is believed that a correct modeling of the pitch control system together with an accurate modeling of the wind turbine aerodynamics will improve the results. The capability of the wind turbine for overproduction can change when considering different manufacturers, especially when considering different turbine inertia constant and $C_{P}$ curve. Nevertheless this analysis provides a base for further studies on VSWT capabilities for future power system solutions.

\section{CONCLUSION}

Modern Variable Speed Wind Turbines (VSWT) present high flexibility for power system solutions. New control systems for VSWT need to be developed in order to provide with ancillary services and grid support from wind power in power systems with high wind power penetration, e.g., inertia response and frequency control.

In this work the capability for providing extra active power output on top of available production was studied on a multimegawatt VSWT-DFIG. Results show a strong dependency on the wind turbine operational states as well as on wind speed conditions. It was found that it is possible to have an active power overproduction of $0.2 \mathrm{pu}$ on top of steadies 0.8 pu for at least 10 seconds, which could be useful for the grid operator for restoring a critical situation of frequency dip, especially in power systems with slow primary movers response or low inertia. Nevertheless it is important to consider the underproduction power and the associated large recovery period that follow a VSWT overproduction operation. The lost energy during an overproduction operation is highly variable; dependant on wind turbine operation as well as on wind speed conditions. Further studies in VSWT frequency response capability need to be carried out, especially considering the interactions of wind turbines in wind farms and coordination. It is important to consider the VSWT's electrical and mechanical components limitations in order to keep the wind turbine operation inside safe margins.

This work provides a base for further studies on VSWT capabilities for new power system solutions. The results are useful in designing overall control scenarios.

\section{REFERENCES}

[1] Ackermann, T.; Abbad, J.R.; Dudurych, I.M.; Erlich, I.; Holttinen, H.; Kristoffersen, J.R.; Sørensen, P.E., "European Balancing Act," Power and Energy Magazine, IEEE, vol.5, no.6, pp.90-103, Nov.-Dec. 2007.

[2] Tarnowski, G.C.; Reginatto, R., "Adding Active Power Regulation to Wind Farms with Variable Speed Induction Generators," Power Engineering Society General Meeting, 2007. IEEE, vol., no., pp.1-8, 2428 June 2007.

[3] Wood, G.F.; Hung, W.W., "Generating plant frequency control services," Frequency Control Capability of Generating Plant, IEE Colloquium on , vol., no., pp.1/1-1/5, 8 Feb 1995.

[4] Yu Chen; Zhao Xu; Ostergaard, Jacob, "Frequency analysis for planned islanding operation in the Danish distribution system - Bornholm," Universities Power Engineering Conference, 2008. UPEC 2008. 43rd International, vol., no., pp.1-5, 1-4 Sept. 2008.

[5] J. morren, J. Pierik, Sjoerd W. H. de Haan, "Inertial Response of Variable Speed Wind Turbines", Electric Power Systems Research, Elsevier, vol. 76, issue 11, July 2006, Pages 980-987.

[6] Ekanayake, J.; Jenkins, N., "Comparison of the response of doubly fed and fixed-speed induction generator wind turbines to changes in network frequency," Energy conversion, IEEE transactions on, vol.19, no.4, pp. 800-802, Dec. 2004.

[7] Ullah, N.R.; Thiringer, T.; Karlsson, D., "Temporary Primary Frequency Control Support by Variable Speed Wind Turbines- Potential and Applications," Power Systems, IEEE Transactions on, vol.23, no.2, pp.601-612, May 2008.

[8] Lalor, G.; Mullane, A.; O'Malley, M., "Frequency control and wind turbine technologies," Power Systems, IEEE Transactions on, vol.20, no.4, pp. 1905-1913, Nov. 2005.

[9] Conroy, J.F.; Watson, R., "Frequency Response Capability of Full Converter Wind Turbine Generators in Comparison to Conventional Generation," Power Systems, IEEE Transactions on , vol.23, no.2, pp.649-656, May 2008.

[10] Tarnowski, G. C; Kjær, P. C.; Sørensen, P. E.; Østergaard, J., "Study on Variable Speed Wind Turbines Capability for Frequency Response", accepted in European Wind Energy Conference EWEC 2009, 16-19 March, Marseille, France, 2009. 